\title{
Cardiology
}

\section{Increasing Availability of the International Normalized Ratio Control in Russia}

\author{
Natalya V. Aksyutina, $\mathrm{PhD}, \mathrm{ScD}^{1^{*}}$; Fyodor G. Zograf, $\mathrm{PhD}^{2}$; Vasily S. Mordovsky ${ }^{1}$; \\ Oksana A. Gavrilyuk, $\mathrm{PhD}^{1}$; Pavel S. Marinushkin, $\mathrm{PhD}^{2}$; Vladimir A. Shulman, $\mathrm{PhD}, \mathrm{ScD}^{1}$; \\ Irina S. Knyazeva ${ }^{1}$; Aleksandr M. Sitnikov²; Mikhail I. Gavrilenko; \\ Viktor V. Kusaev, $\mathrm{PhD}^{1}$; Elena E. Aldanova ${ }^{1}$ \\ IProfessor V.F. Voino-Yasenetsky Krasnoyarsk State Medical University \\ ${ }^{2}$ Siberian Federal University \\ Krasnoyarsk, the Russian Federation
}

\begin{abstract}
Background: Warfarin is still, in some cases, the only medication to prevent thromboembolic complications. Warfarin intake imposes regular INR monitoring, which can be performed domiciliary. Currently, in the Russian market, there are two models of automatic portable blood coagulometers: CoaguChek XS (Germany) and qLabs ElectroMeter (China). The main problem of portable coagulometers is their high cost and high cost of operation, which the majority of patients cannot afford. To explore the demand for development of a Russian coagulometer with a more affordable price, a questionnaire survey was carried out among the patients who needed this device.

Methods and Results: We surveyed 70 patients taking Warfarin, with 5 years duration paroxysmal, persistent/or stable atrial fibrillation of nonvalvular etiology, having $\geq 2$ CHADS-VASc score for thrombembolia risk assessment and $\leq 3$ HAS-BLED score for hemorrhage risk assessment. According to the survey results, $7(10 \%)$ patients had portable coagulometers, including 3 persons with CoaguChek XS and 4 persons with Micropoint qLabs ElectroMeter. Among these patients, there were 4 persons who continued regular INR monitoring domiciliary, while 3 patients had financial difficulties in getting testing strips. At the same time, $14(20 \%)$ patients were not aware of the possibility of domiciliary INR monitoring. Patients who received regular INR monitoring domiciliary with a portable coagulometer, or at their local polyclinics, had neither ischemic strokes nor hemorrhages within a period of five years.

Conclusion: It is critical to develop and manufacture a domestic equivalent of a portable coagulometer and testing strips for household use at a more affordable price. (International Journal of Biomedicine. 2018;8(4):292-295.)
\end{abstract}

Key Words: portable coagulometers • international normalized ratio $\bullet$ atrial fibrillation $\bullet$ Warfarin

\section{Abbreviations}

INR, international normalized ratio; PT, prothrombin time; TP, thromboplastin; ISI, international sensitivity index.

\section{Introduction}

In spite of a wide choice of modern, indirect oral anticoagulants that do not require the INR control, Warfarin is still, in some cases, the only medication to prevent

*Corresponding author: Natalya V. Aksyutina, PhD, MD. Krasnoyarsk State Medical University n. a. Prof. V.F. Voino-Yasenetsky, Krasnoyarsk, the Russian Federation. E-mail: aks-n-v@yandex.ru thromboembolic complications in pediatrics, in cases of atrial fibrillation of valve etiology, heart valve replacement, and clots in the formed aneurism as a result of an acute myocardial infarction..$^{(1-3)}$

The history of Warfarin discovery goes back to 1920s, when in North Dakota (USA) the cattle started to die of a fatal-sometimes spontaneous - bleeding after such minor traumas as dehorning or castration. Carrying out the postmortem study of those animals, F. Schofield detected some 
sweet clover (Melilotus alba and M. officinalis) in the intestine of a dead cow. F. Schofield suggested that spoilt clover caused an unknown disease, and proved his assumption by his study on rabbits. In 1933, a group of scientists-chemists under the guidance of K.P. Link managed to obtain and identify a substance from spoilt hay that was later named dicumarol. In 1936, H. Dam established that the cause of an increased bleeding was that dicumarol brought down the liposoluble vitamin $\mathrm{K}$ level. Initially dicumarol was used as a rat poison named WARFARIN, and in 1947, it was used for the first time as a medicament to treat an acute myocardial infarction. ${ }^{(4,5)}$

The mechanism of dicumarol action is due to a decrease in the synthesis and functional activity of blood clotting factors (II, VII, IX, X) and the loss of their ability to bind to phospholipids. This is connected to impaired decarboxylation and carboxylation of proteins dependent on vitamin $\mathrm{K}$ due to inhibition of the enzyme vitamin $\mathrm{K}$ oxide reductase in the liver. ${ }^{(6)}$

Taking Warfarin involves regular monitoring of the extrinsic pathway of blood coagulation, because as an antagonist of vitamin $\mathrm{K}$, its effectiveness changes depending on the number of products containing vitamin $\mathrm{K}$ and functional characteristics of the liver. A method for determining prothrombin time (PT) was introduced into practice by A.J. Quick $^{(1,2,7)}$ in 1935. PT is the period of time during which plasma coagulation occurs with the formation of a clot after Thromboplastin (TP) and calcium chloride are added to it. TP is a lipidized tissue factor obtained by extracting salt from tissues of mammals or by genetic engineering. ${ }^{(7,8)}$ The activity of the extrinsic and common pathways of blood coagulation and characteristics and concentration of TP can influence the results of PT. ${ }^{(7)} \mathrm{PT}$ can be shown in three variants: The first one is the clotting time in seconds. The second variant shows prothrombin index. The third variant represents the prothrombin ratio: $\frac{P T 100 \%}{P T p}$, where

PTp is PT of patient plasma (in seconds) PT 100\% is PT of pool of fresh donor plasma that contains $100 \%$ of clotting factors (in seconds).

However, it turned out that different laboratories could obtain different results of PT. Possible reasons for the variations in these indicators are the use of different TPs, and sampling and evaluation techniques. In order to standardize the test, it was decided to take into account the degree of TP activity in the form of international sensitivity index (ICI).

ICI shows the ability of TP to change the plasma clotting time depending on the deficiency of factors II, VII and $\mathrm{X}$. WHO ordered producers to compare their TP with the reference, which was accepted as the unit. In 1983, the following formula of INR with ISI was accepted and put into practice: $\left(\frac{P T 100 \%}{P T p}\right)^{I S I}$

In addition to the sensitivity of TP, the results of the prothrombin test can be influenced by the equipment used to measure the time of clot formation (types of coagulometers). Therefore, to avoid inaccuracy, thromboplastin manufacturers release reagents adapted to the methods of fibrin clot registration. ${ }^{(7-9)}$

If a patient takes Warfarin regularly, frequent repeated INR evaluation is required. Over the most recent years, it has become more popular to evaluate INR in capillary blood; it makes blood sampling easier, and the volume of blood necessary for testing is smaller. Despite these obvious advantages, some difficulties arise. The major problem is in a high risk of blood contacting the thrombogenic tissue surface, which can trigger the coagulation process much sooner that would result in a preanalytical error. Another difficulty is the calibration of the proper quality control system for prothrombin test methods proposed by domestic thromboplastin producers. In these methods, whole blood and regular TP are used. Whole blood has a higher density and viscosity than plasma, which leads to a hampered blending of the reaction mixture in the blood coagulometer, and which in turn yields a faulty result. A possible way to solve this problem is by applying combined reagents whose composition, apart from TP, includes fibrinogen and V factor, which allows decreasing the capillary blood volume to $10-20 \mu \mathrm{l}(1 / 20$ of the medium volume). A high percentage of the sample dilution allows using lyophilizated plasmas in the ratio of $1 / 2$ of blood volume for the quality control. In this case, one can disregard the influence of blood cells $(<3 \%$ of the reaction mixture). When whole blood in used, the hematocrit affects the result significantly. In this connection, a nomogram is necessary to compensate for the influence of hematocrit. The above-stated problems were solved in portable blood coagulometers by means of pre-calibrated test strips containing TP (usually TP of genetically engineered origin is used). ${ }^{(7,8)}$

Currently, in the Russian market, there are two models of automatic portable blood coagulometers that can be used by patients at home (CoaguChek XS portable coagulometer and qLabs ElectroMeter). They have similar characteristics and are easy to use (Table 1).

Table 1.

Portable coagulometers performance comparison

\begin{tabular}{|l|l|l|}
\hline \multicolumn{1}{|c|}{ Specifications } & \multicolumn{1}{|c|}{ CoaguChek XS } & qLabs ElectroMeter \\
\hline Country of origin & Germany & China \\
\hline Sample type & $\begin{array}{l}\text { Fresh whole capillary } \\
\text { blood or whole venous } \\
\text { blood }\end{array}$ & $\begin{array}{l}\text { Fresh whole } \\
\text { capillary blood }\end{array}$ \\
\hline Instrumental error & $\begin{array}{l}\text { Maximal instrumental } \\
\text { error in case of capillary } \\
\text { blood analysis - } \pm 4.5 \%, \\
\text { in case of venous blood } \\
\text { analysis - } \pm 3.5 \%\end{array}$ & $<5 \%$ \\
\hline Measurement range & $0.8-8$ & $0.5-7.5$ \\
\hline Measurement method & Electrochemical & Electrochemical \\
\hline Connection with PC & $\begin{array}{l}\text { With the use of } \\
\text { Coaguchek XS } \\
\text { Connect device (is not } \\
\text { a part of package) }\end{array}$ & $\begin{array}{l}\text { With the use of } \\
\text { (supplied as part of } \\
\text { package) }\end{array}$ \\
\hline $\begin{array}{l}\text { Weight } \\
\text { Price as of August 24, } \\
\text { 2018 from a substantive } \\
\text { analysis of suppliers } \\
\text { pricing }\end{array}$ & From 35,500 RUB & $\begin{array}{l}\text { From 126 g } \\
\text { (without batteries) }\end{array}$ \\
\hline $\begin{array}{l}\text { Testing strips price as } \\
\text { of August 24, 2018 }(24 \\
\text { pcs.) from a substantive } \\
\text { analysis of suppliers } \\
\text { pricing }\end{array}$ & $\begin{array}{l}\text { From7,100 RUB } \\
\text { (item - 295.83 RUB) }\end{array}$ & $\begin{array}{l}\text { From 5,300 RUB } \\
\text { (item - 220.8 RUB) }\end{array}$ \\
\hline
\end{tabular}


The main problem of portable coagulometers is their high cost and high cost of operation, which the majority of patients cannot afford. That is why, in many sparsely populated areas situated far from certified laboratories, INR control is still a problem. The appearance of a less expensive domestic analogue would probably help to partially solve this problem.

\section{Materials and Methods}

To explore the demand for development of a Russian coagulometer with a more affordable price, a questionnaire survey was carried out among the patients who needed this device.

We surveyed 70 patients (26 males and 44 females) taking Warfarin, with 5 years duration paroxysmal, persistent/ or stable atrial fibrillation of nonvalvular etiology, having $\geq 2$ CHADS-VASc score for thrombembolia risk assessment and $\leq 3$ HAS-BLED score for hemorrhage risk assessment. The patients' median age was 59.00 [47.00-65.00] years. All the study participants were Krasnoyarsk city residents. The present study was approved by the local Ethics Committee of Professor V.F. Voino-Yasenetsky Krasnoyarsk State Medical University (Record No. 88 dated 06.06.2018). Written informed consent was obtained from each patient.

Before the survey, patients were informed of the possibility of performing INR domiciliary with a portable coagulometer, as well as of comparative characteristics of portable coagulometers (Table 1). A special workshop was conducted to teach the patients how to monitor INR with a portable coagulometer (CoaguChek XS or Micropoint qLabs ElectroMeter).

\section{Results}

Single INR measurement showed a therapeutic range from 2 to 3 in all patients. According to the survey results, 7 (10\%) patients had portable coagulometers, including 3 persons with CoaguChek XS and 4 persons with Micropoint qLabs ElectroMeter. Among these patients, there were 4 persons who continued regular INR monitoring domiciliary, while 3 patients had financial difficulties in getting testing strips.

Further survey questions allowed us to reveal the reaons why $63(90 \%)$ patients did not buy portable coagulometers to control their INR. Among these patients, there were 19 (30.2\%) who received regular INR monitoring at their local polyclinics and 31 (49.2\%) who received irregular INR monitoring at their local polyclinics. These patients wanted to buy a portable coagulometer, but could not afford it. At the same time, 13 (20.6\%) patients did not realize the significance of regular INR monitoring (Figure 1).

Moreover, it should be indicated that $14(20 \%)$ patients were not aware of the possibility of domiciliary INR monitoring. Among them, there were $4(28.6 \%)$ patients who received regular INR monitoring at their local polyclinics and 5 (35.7\%) patients who received irregular INR monitoring at their local polyclinics. These patients wanted to buy a portable coagulometer, but could not afford it, and 5 (35.7\%) patients were not aware of the possibility and significance of domiciliary INR monitoring.

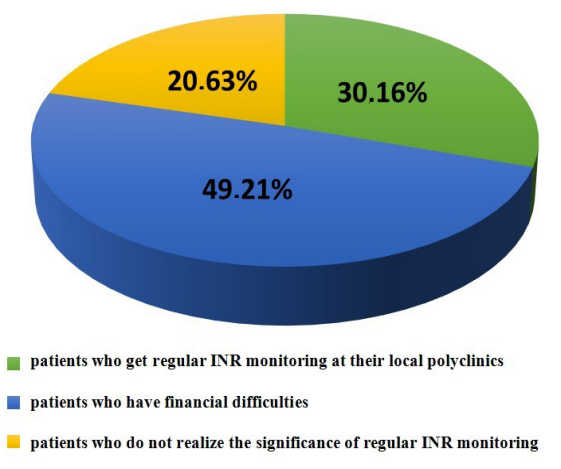

Fig. 1. Reasons why the patients who needed regular INR monitoring did not buy portable coagulometers.

As it turned out, those patients who received regular INR monitoring domiciliary with a portable coagulometer, or at their local polyclinics, had neither ischemic strokes nor hemorrhages within a period of five years.

Among $44(62.8 \%)$ patients without regular INR monitoring, atrial fibrillation was complicated by ischemic stroke in $5(11.4 \%)$ persons and by different hemorrhages in $7(15.9 \%)$ persons (Figure 2).

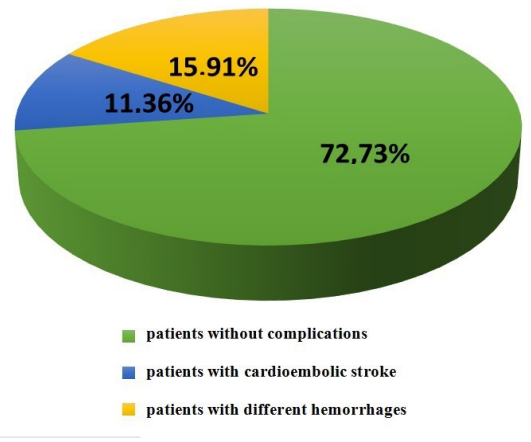

Fig. 2. Complications in patients who did not have regular INR monitoring.

\section{Discussion}

The results described above indicate that it is critical to develop and manufacture a domestic equivalent of a portable coagulometer and testing strips for household use at a more affordable price.

Up to now, the problem of INR control, especially for patients whose mobility is limited or those who live far from big towns and cities, is still urgent. There is still a high frequency of complications resulting from taking antagonists of vitamin $\mathrm{K}$, such as bleeding and an inadequate therapeutic effect of medication due to improper INR control. ${ }^{(1-3)}$ Informing patients and doctors about the possibilities provided by modern, automatic, portable blood coagulometers will allow improving 
INR control; and using portable blood coagulometers by means of telemedicine and/or special apps for telephones will also allow improving INR control and decreasing the load on the medical network, resulting in lower public health expenses. ${ }^{(10,11)}$

\section{Sources of Funding}

The reported study was funded by Krasnoyarsk Regional Fund of Science according to the research project: "Development of a portable coagulometer for monitoring of the international normalized ratio."

\section{Conflict of interest}

The authors declare that they have no competing interests.

\section{References}

1. Kirchhof P, Benussi S, Kotecha D, Ahlsson A, Atar D, Casadei B, et al. 2016 ESC Guidelines for the management of atrial fibrillation developed in collaboration with EACTS. Rev Esp Cardiol (Engl Ed). 2017 Jan;70(1):50. doi: 10.1016/j. rec.2016.11.033. [Article in English, Spanish].

2. Bernaitis N, Badrick T, Davey AK, Crilly J, AnoopkumarDukie S. Warfarin control in patients transitioning to warfarin after non-vitamin $\mathrm{K}$ oral anticoagulant (NOAC) therapy. J Thromb Thrombolysis. 2018;46(4):461-465. doi: 10.1007/ s11239-018-1719-x.

3. Skaistis J, Tagami T. Risk of Fatal Bleeding in Episodes of Major Bleeding with New Oral Anticoagulants and Vitamin
K Antagonists: A Systematic Review and Meta-Analysis. PLoS One. 2015 Sep 18;10(9):e0137444. doi: 10.1371/journal. pone.0137444. eCollection 2015.

4. Bogachev VYu. Warfarin. Death is postponed. Regular Issues of the Russian Medical Journal. 2013;21(15):797-807.

5. Keller C, MatzdorffAC, Kemkes-Matthes B. Pharmacology of warfarin and clinical implications. Semin Thromb Hemost. 1999;25(1):13-6.

6. Yavelov IS. [Antagonists of Vitamin $\mathrm{K}$ in the prevention and treatment of thrombosis and thromboembolism: updated recommendations of the American College of Thoracic Doctors]. Atherothrombosis. 2009;1(2):55-76. [Article in Russian].

7. Berkovsky AL, Sergeeva EV, Prostakova TM, Melkumyan AL, Suvorov A. Screening tests of plasma hemostasis, Prothrombin time, APTT, Thrombin time, Fibrinogen. Moscow; 2016.

8. Titaeva EV, Dobrovolsky AB. Possible sources of errors in the determination of INRs and ways to solve them. Atherothrombosis. 2015;(2):107-114.

9. WHO Expert Committee on Biological Standartization. Guidelines for Thromboplastins and Plasma Used to Control Oral Anticoagulant Therapy. Annex 3. World Health Organ Tech Rep Ser. 1999;889:64-93

10. Brasen CL, Madsen JS, Parkner T, Brandslund I. Home Management of Warfarin Treatment Through a Real-Time Supervised Telemedicine Solution: A Randomized Controlled Trial. Telemed JE Health. 2018 Jun 7. doi: 10.1089/tmj.2017.0260. [Epub ahead of print].

11. Smaradottir B, Martinez S, Borycki E, Loudon G, Kushniruk A, Jortveit J, Fensli R. User Evaluation of a Smartphone Application for Anticoagulation Therapy. Stud Health Technol Inform. 2018;247:466-470. 